\title{
A ESCOLA DE CHICAGO DE SOCIOLOGIA: \\ O QUE A TORNOU UMA ESCOLA? *
}

\section{Martin BULMER}

Por que, durante os anos de 1920, a Universidade de Chicago foi um centro tão criativo para o desenvolvimento da Escola de Chicago de Sociologia? Como e por que, entre 1915 e 1935, a sociologia floresceu tão notavelmente na Avenida Midway, numa universidade que, desde a sua fundação em 1892, exerceu uma influência muito desproporcional sobre o desenvolvimento das ciências sociais nos Estados Unidos? Não só Chicago foi o centro principal da sociologia no mundo nesse período, mas a característica da abordagem do departamento era a de um esforço intelectual amplo e coletivo. E a sociologia não foi um caso único: a escola de Chicago de filosofia, fundada por John Dewey, estava no auge de sua influência. A escola de Chicago de ciência política estava ganhando força e reputação. A escola de Chicago de economia já apontava no horizonte.

As escolas de ciência social, particularmente aquelas comprometidas o suficiente com a investigação empírica sistemática, são incomuns para que mereçam alguma consideração. A maioria dos departamentos universitários de sociologia constitui um aglomerado de scholars mais ou menos independentes, que perseguem interesses diversos, ou individualmente ou em pequenos grupos. Cooperam entre si para fins de ensino e administração, mas na pesquisa seguem seu próprio caminho. Qualquer sugestão de que poderia haver algum programa de pesquisa integrado no departamento ou de que os indivíduos deveriam integrar sua pesquisa em torno de certos temas, idéias ou problemas centrais, seria considerada pela maioria dos sociólogos acadêmicos como anátema. Todavia, a escola durkheimiana foi um empreendimento coletivo como esse (BESNARD, 1983). Na antropologia social, as "escolas” associadas a Bronislaw Malinowski na London School of Economics nos anos de 1920 e 1930 e a Max Glukman no Instituto Rhodes-Livingstone na Rodésia do Norte [atual Zâmbia] e na Universidade de Manchester nos anos de 1940 e 1950 produziram muitos trabalhos importantes (KUPER, 1983, p. 1-35; 142-155). Embora este artigo esteja fundamentalmente interessado na sociologia de Chicago, volta-se algumas vezes de relance para essas outras "escolas".

\footnotetext{
* Este artigo foi apresentado no encontro anual da Associação Americana de Sociologia em 27 de agosto de 1984 em San Antonio, Texas, e publicado sob o título: "The Chicago School of Sociology: What Made It a 'School'?" em: History of Sociology: An International Review - vol. 5, n. ${ }^{\circ}$, Spring 1985, pp: 61-77 [N. do T.].
} 
Uma "escola" nas ciências sociais pode ser pensada como afim ao termo usado em história da arte para designar um grupo de contemporâneos que compartilha de um certo estilo, técnica ou conjunto de expressões simbólicas e que têm em algum ponto ou outro do espaço ou do tempo um alto grau de integração (por exemplo, os impressionistas, a Escola da Bauhaus etc.). Um exemplo local seria a escola de Chicago de Arquitetura, centrada em Louis Sullivam e Frank Lloyd Wright (CONDIT, 1964; DUNCAN, 1965; SIEGEL, 1969, p. 3-26).

Numerosas características típico-ideais podem ser observadas que distinguem uma escola de ciência social. Ela tem um fundador-líder e seus seguidores, usualmente abrangendo, em termos de tamanho, entre uma e três dúzias de membros. Esse líder tem uma personalidade relativamente dominadora. Seus membros são usualmente unidos por um conjunto de idéias, crenças e disposições normativas, articuladas pelo fundador-líder, que apresentam alguma divergência com aquelas predominantes na disciplina na época. Uma escola tipicamente busca modernizar ou renovar a disciplina. Ela consiste em uma comunidade científica integrada em torno de uma figura central, um líder intelectual carismático, e de um paradigma da realidade empírica que é submetida a investigação. As formulações do núcleo do paradigma são aquelas do fundador-líder, mas o paradigma plenamente desenvolvido é tipicamente um empreendimento coletivo, moldado pelo fundador-líder e sua entourage imediata. (TIRYAKIAN, 1979, p. 218-219).

As escolas florescem em cenários com afiliação institucional, tipicamente um local acadêmico de excelência geral numa grande área metropolitana. Um periódico, uma revista ou outros meios de publicar regularmente a pesquisa é exigido para se comunicar com um público acadêmico mais amplo, assim como para integrar as atividades dos membros dispersos da escola. Uma escola é assim consideravelmente mais do que uma coleção de ilustres scholars individuais num departamento líder. Implica a existência de atividade acadêmica em colaboração integrada por meio do trabalho de uma ou mais figuras líderes da escola.

O termo 'escola' não é usado neste artigo em dois outros sentidos, para fazer referência a escolas de pensamento ou a seguidores póstumos de um sociólogo particular. Sorokin, por exemplo, em Contemporary Sociological Theories (1928), tratou como pertencendo a uma escola de pensamento cientistas sociais que poderiam estar separados no tempo e/ou no espaço mas compartilhavam uma abordagem, teoria ou método reconhecivelmente comuns, mesmo se nunca tivessem tido contato uns com os outros. Esse é um uso muito diferente, que amplia o termo até o limite da credibilidade. Um uso diferente está na "escola de Le Play" de Patrick Geddes e Victor Branford na Grã-Bretanha nos primeiros anos do século XX (SILVER, 1982, p. 123-124; ABRAMS, 1968, p. 101-120; KITCHEN, 1975; BOARDMAN, 1978; MUMFORD, 1982; BULMER, 1984b). Iniciando bem depois da morte de Le Play, Geddes e Branford acreditavam que estavam criando um 
grupo, centrado finalmente na Le Play House em Londres, que levaria adiante suas idéias. O uso de "escola" neste artigo se refere a uma coletividade existente na mesma época e lugar que a figura dominante, usualmente envolvendo um alto grau de contato face a face e laços pessoais entre os membros do grupo.

O uso mais antigo do termo "escola de Chicago" parece ser o de L. L. Bernard (1930, p.133), embora o termo não estivesse em uso na Universidade de Chicago nos anos de 1920 (CAVAN, 1983, p. 408). A existência da escola de Chicago é documentada em certo número de histórias clássicas, tais como as de Faris ((1967) 1970), Carey (1975) e Raushenbush (1979), muitos dos volumes da série The Heritage of Sociology [A Herança da Sociologia] (particularmente Short 1971) e na iluminadora biografia de Robert Park por Fred Matthews (1977), que inclui o termo em seu sub-título. Shils $(1970,1980)$ discute isso entre as outras características da sociologia de Chicago, mas da perspectiva ligeiramente diferente da institucionalização acadêmica da disciplina, que não exige a formação de escolas para ser efetiva. Tiryakian (1979, p. 226-228) faz alguns breves comentários sugestivos, enquanto Wiley (1979) assume a integração da escola como assentada e a compara com outros departamentos líderes do período.

Podem-se identificar nove características que contribuíram para a criação e sustentação da escola de Chicago de sociologia. Algumas delas foram identificadas por autores anteriores que escreveram sobre o assunto, outras não. O foco desta discussão é sobre as condições que levaram à formação de uma escola, não a outros aspectos da sociologia de Chicago (como, por exemplo, em LEWIS; SMITH, 1980; BENNETT, 1981 ou THOMAS, 1983).

Uma escola exige uma figura central em torno de quem ela se organiza. Durkheim, Malinowski e Gluckman foram indivíduos por meio de quem seu grupo de pesquisa foi liderado e que deram a ele sua identidade. Todavia, o tipo ideal não permite a liderança conjunta e esse foi o caso da escola de Chicago. O período de tempo em que estamos interessados é amplamente pensado como o da década de 1920, mas pode de fato ser recuado para 1913, quando Park juntou-se a William I. Thomas no departamento de Chicago e trabalhou com ele até a demissão de Thomas em 1918 (JANOWITZ, 1966, p. xiv-Xvi). Thomas foi o progenitor intelectual da investigação empírica no departamento de Chicago, um importante teórico e um autor cuja marca, tanto por meio de sua associação com Park como através da influência de seus escritos, estendeu-se ao longo da década de 1920. Os interesses de pesquisa de Thomas e de Park se superpuseram de maneira particularmente estreita nos campos de raça e etnicidade e, depois de 1918, eles completaram, como parte do Projeto da Americanização da Fundação Carnegie, a monografia Old World Traits Transplanted (PARK; MILLER, 1921), embora a colaboração de Thomas não tenha podido ser reconhecida na publicação e somente foi revelada trinta anos depois. Robert Park foi a figura central e líder da escola de Chicago, 
mas esses primeiros frutíferos anos trabalhando com Thomas são com freqüência negligenciados. O próprio Park foi bastante claro a respeito de sua importância, como reconheceu explicitamente em 1939 para a Society for Social Research [Sociedade de Pesquisa Social] (KURTZ, 1982; BULMER, 1983).

Depois de 1918, Robert Park e Ernest Burgess estiveram estreitamente identificados, dividindo um gabinete na torre leste da Harper Library [Biblioteca Harper] e planejando juntos o programa de estudos urbanos que é uma das características da escola (BURGESS, 1964; COTTRELL, 1973). A contribuição particular feita por Burgess foi a de facilitar e dar o principal apoio para a pesquisa empírica. Sem ele, as idéias de Park provavelmente não teriam sido transformadas em pesquisa de substância material (BULMER, 1984a). Assim, a liderança da escola foi compartilhada, primeiro entre Thomas e Park, depois entre Park e Burgess. Foi de Park a contribuição e o intelecto dominantes, mas é o caso de lembrar que pode haver uma ou duas figuras à testa de uma escola. A gênese da escola de Chicago de economia durante a década de 1930 sob Frank Knight e Jacob Viner é outro caso interessante de uma escola com liderança dupla.

As escolas de sociologia são fenômenos do mundo acadêmico. Subsistem em universidades e exigem estudiosos como parte necessária e integral de sua atividade. A segunda característica da escola de Chicago foi que sua localização universitária era particularmente propícia para incentivar uma atividade intelectual séria. Desde sua fundação em 1892, a Universidade de Chicago colocou particular ênfase no desempenho de pesquisa e de padrões de atividade acadêmica. Esperava-se uma pesquisa significativa de seu corpo docente e se estimulava a publicação. Atribuía-se maior importância à formação de pós-graduandos em pesquisa do que ao ensino de graduandos do que era comum nas universidades do mundo de fala inglesa. No início, e mesmo na década de 1920, encontrou pouca competição por parte das velhas colleges, ou faculdades, reformadas de Oxford e Cambridge e das numerosas faculdades de ensino de graduação de toda América do Norte, ou mesmo das faculdades de universidades ilustres, tais como Yale e Harvard. A sociologia, por exemplo, só veio a se estabelecer em Harvard em 1930 e enlanguesceu em Yale sob o sucessor de Sumner, que somente lecionava para alunos de graduação. A ecologia da vida acadêmica em Chicago foi também de importância e incentivou o intercâmbio intelectual (SHILS, 1970). A maioria dos membros da universidade morava no campus ou próximo a ele. Os sociólogos compartilhavam prédios para ensino e pesquisa e, depois de 1929, um único prédio (o de número 1126 [da East 59. ${ }^{\text {th }}$ Street]) que alojou todas as ciências sociais.

A tendência de Chicago de produzir escolas - academicamente de sociologia, ciência política e economia, culturalmente de arquitetura e literatura - pode também ser considerada em termos de 
qualidades distintivas da cidade e da relação da universidade com ela. A universidade não era isolada da cidade em que estava localizada. Os membros das equipes da universidade estavam fortemente envolvidos em questões locais desde o início, proporcionando uma orientação e um conjunto de vínculos que ajudavam a estimular a pesquisa local (DINER, 1980; CAREY, 1975; HUNTER, 1980). O envolvimento de Park com a Chicago Urban League, [Liga Urbana de Chicago], por exemplo, levou diretamente à contratação de Charles Johnson como diretor de pesquisa para a Riot Comimission, ou Comissão do Conflito Racial, e sua colaboração com Park que produziu The Negro in Chicago (Chicago Commission 1922; BULMER, 1981a).

A comunidade local foi o foco de quase toda a pesquisa em sociologia e ciência política durante a década de 1920. Isso deu àqueles envolvidos um esquema delimitado dentro do qual trabalhar. O programa de Park e Burgess de pesquisa urbana, em muitos pontos bastante difuso e impreciso, ganhou coerência e importância por estar sendo levado adiante no interior de um cenário local específico. De modo semelhante, os surveys pioneiros de ciência política de Merriam se tornaram passíveis de aplicação (e em alguma medida evitando os problemas de amostragem) por serem estudos de comportamento político no interior da cidade (KARL, 1974, p. 140-156).

Também foi sugerido que, como cidade, Chicago tem sido mais tolerante para com a diversidade intelectual do que a cidade de Nova York.

A grande boa sorte de nossa universidade foi a de que não estava estabelecida na Costa Leste. (...) Felizmente nos estabelecemos em Chicago, uma cidade nova e rude, cheia de energia, bem menos sofisticada do que Nova York, mas por essa mesma razão bem mais tolerante com a diversidade e as idéias heterodoxas. (...) Chicago caracterizava-se por diversidade em todas as dimensões, por uma disposição de experimentar, de julgar as pessoas pelo seu desempenho mais do que por suas origens, de julgar as idéias por suas conseqüências mais do que por seus antecedentes (FRIEDMAN, 1974, p. 7).

Assim, ela pôde incentivar, num período posterior, uma escola de economia cujos principais pontos de vista estavam em desacordo com aqueles das principais universidades da Costa Leste. Certamente a base de Chicago pareceu estimular W. I. Thomas a alturas que nunca veio a alcançar depois de 1918, quando foi morar em Nova York. Willard Waller, num período posterior, dissipou a maior parte de suas energias acadêmicas quando se mudou para a cidade de Nova York (GOODE, 1970, p. viii-ix). Lasswell nunca atingiu posteriormente as alturas que alcançou em Chicago depois que partiu em 1938 (SHILS, 1981).

Essas qualidades gerais da universidade e da cidade somente poderiam ser condições necessárias, mas não suficientes. Uma quarta característica da escola de Chicago, como de outras escolas, foi a personalidade dominadora de sua figura chave, Robert Park. Thomas, sozinho, não teria 
criado a escola de Chicago e depois da aposentadoria de Park, em 1934, Burgess, sozinho, não pôde mantê-la. Uma das características comuns aos líderes de escolas de ciência social de Chicago era serem professores inspiradores e eficientes. Park suscitava a curiosidade de seus alunos, confiava em suas capacidades e os incitava para o estudo empírico dos fenômenos em que estava interessado, complementado pelas habilidades mais práticas de Burgess. Charles Merriam em ciência política não teve a curiosidade intelectual ou o aguçado insight de Park. No centro de seu pensamento havia um elemento retórico que diminuiu seu impacto. Mas foi capaz de buscar aquela qualidade de curiosidade em outros, tais como Harold Lasswell e Harold Gosnell, e estimulá-la. Acoplando sua visão quantitativa e científica da ciência política e sua capacidade administrativa e organizacional (que era bem superior à de Park), ele criou sem ajuda a escola de ciência política. "Foi o departamento que se engajou em pesquisa e os projetos anunciados para a profissão em vários momentos eram referidos como empreendimentos departamentais. Não se diferenciavam os membros juniors dos membros seniors em tais anúncios e as citações em conjunto eram o costume. O departamento de Chicago foi concebido por Merriam como uma comunidade de pesquisa." (KARL, 1974, p. 145). Em economia, um pouco mais tarde, Frank Knight reuniu ao seu redor um grupo informal de estudantes e de protegidos, que incluía Henry Simons, Milton Friedman, Aaron Director, George Stigler e Allen Wallis, que no futuro vieram a constituir uma escola (REDER, 1982, p. 5-6).

Líderes acadêmicos, tais como Park, inspiravam admiração e lealdade pessoal de seus colegas e estudantes. Eles sustentavam a integração no interior do departamento e evitavam a fissão. Eles procuravam colaboradores talentosos para participar na pesquisa que orientavam. A dominância, todavia, não significava que se esperava que todos os estudantes reproduzissem os pontos de vista de seu professor. Havia um grau de abertura em torno das escolas de Chicago de sociologia e de ciência política que em parte explica seu sucesso. Park proporcionou um esquema um tanto impreciso para a pesquisa em seu ensaio sobre "The City", de 1915, que Burgess desenvolveu com a teoria das zonas concêntricas (PARK; BURGESS, 1925). No interior disso, os estudantes eram encorajados a investigar de maneira não dogmática. O esquema de Merriam tinha mais a natureza de uma orientação metodológica geral, mas com aquela mesma qualidade de abertura. $\mathrm{O}$ contraste não podia ser maior com aqueles que não foram bem sucedidos em promover a sociologia, tais como Franklin Giddings, chefe até 1927 do departamento de sociologia de Columbia, que rivalizou com Chicago nos primeiros anos do século, mas que por volta de 1920 era apenas uma pálida sombra.

Seu dogmatismo, presunção e preconceitos pessoais alienaram muitos membros proeminentes e influentes do corpo docente de Columbia, que viram diante disso que a sociologia não se expandiria ali até que Giddings se aposentasse. O próprio Giddings contribuiu para isso cercando-se de homens de segunda linha que não fossem uma ameaça à sua liderança. De acordo com aqueles que o 
conheceram pessoalmente, ele era antissemita e tinha pobres relações com cientistas sociais notáveis de Columbia, como Boas e Seligman, porque eles eram judeus. (OBERSCHALL, 1972, p. 226).

Park, em contraste, era infinitamente curioso a respeito da relevância das idéias de outras disciplinas para a sociologia, tinha cordiais relações pessoais com colegas de outros departamentos e por seu interesse pelos grupos étnicos estava isento de muitos dos preconceitos convencionais da época. Não foi por acidente que dois dos mais notáveis dos primeiros sociólogos negros, Charles S. Johnson e E. Franklin Frazier, tenham sido seus estudantes. O contraste entre Park e Giddings exemplifica o ponto de que o líder de uma escola deve infundir respeito e afeição sem espantar a originalidade e a criatividade intelectuais em seus estudantes e protegidos.

A mais importante característica do líder ou líderes de uma escola é que eles devem possuir uma clara visão intelectual e um impulso missionário. Que isso venha em quinto lugar não diminui sua extrema importância. Uma escola exige um esquema intelectual coerente e distinguível em seu núcleo, que pode ser proporcionado por uma nova teoria ou teorias e/ou novos métodos de pesquisa e/ou um forte compromisso com um tipo particular de investigação empírica. No centro de qualquer escola acadêmica estão um ou dois indivíduos com um corpo de idéias ou uma visão que se impõe e que atrai outros, mantém o grupo unido e dá a ele um maior grau de coesão intelectual do que é usual entre colegas em departamentos acadêmicos de ciência social. Uma escola é, enfim, a consequência daquela qualidade pessoal de paixão ou autoconfiança intelectual que emana de um ou dois indivíduos que se situam a alguma distância de seus colegas. A dependência das escolas em relação às suas figuras líderes é muito impressionante. Albion Small criou as condições depois de 1892, mas foi só quando Thomas trouxe Park para Chicago em 1913 que a escola de Chicago começou a se desenvolver. No caso de Merriam, o início foi até menos propício, devido a um antagonismo com o presidente da universidade (que também era o chefe do departamento de ciência política), até 1923.

A dominância intelectual poderia assumir várias formas. Escolas posteriores, tais como aquelas de Malinowski e de Gluckman, tinham uma teoria mais explícita em seu centro do que no caso daquelas em torno de Park e em torno de Merriam. A sociologia e a ciência política de Chicago não obstante tinham uma teoria geral implícita e uma clara visão intelectual. Na sociologia diversos elementos eram distintivos. As idéias gerais de Park a respeito do processo social e do controle social ligaram-se à teoria ecológica para se centrarem sobre a cidade. Os processos de competição, conflito, acomodação e assimilação foram o interesse central e puderam ser usados para explicar a "história natural" de grupos particulares (TURNER, 1967; COSER, 1978). A formulação de Burgess da hipótese das zonas concêntricas e a classificação da metrópole em 75 áreas naturais identificaram os milieux em que os estudos poderiam ser conduzidos (HUNTER, 1974). A metáfora da grande cidade como um laboratório social proporcionou um fundamento racional para uma série de estudos de 
campo intensivos. A sociologia de Chicago trouxe as marcas das origens de Park como jornalista Park não procurava uma síntese teórica como Malinowski, por exemplo - mas não obstante houve elementos teóricos fortes implícitos em sua abordagem.

O termo 'escola' algumas vezes tem conotações de uma facção ou grupo restrito ou de um culto. Com certeza envolve usualmente a aceitação das idéias centrais da(s) figura(s) líder(es) pelos membros, que são usualmente distintas daquelas predominantes na disciplina na época. Uma escola deve, portanto, reivindicar sua originalidade nas idéias ou na abordagem que adota. Uma certa paixão é também necessária, uma crença de que as idéias ou abordagens predominantes carecem do firme apoio no mundo social que a abordagem da escola incorpora. Todavia, uma amplitude de visão mais do que uma estreiteza de vistas é também um pré-requisito e isso os grupos de estudiosos ao redor de Park e de Merriam possuíam. No caso da sociologia de Chicago, um pouco da falta de restrição deveuse a certa imprecisão da teoria de Park e da liberdade dos estudantes para investigar amplamente tipos variados de vida urbana em meios muito diferentes, tão extremos quanto a Gold Coast e o slum.

A seguir em importância para a visão intelectual está uma sexta característica, a gravidade, seriedade e intensidade dos intercâmbios intelectuais entre o líder e os outros membros do grupo, quer estes sejam colegas ou estudantes de pós-graduação. Tais redes acadêmicas são mais fortemente unidas do que é usual em disciplinas ou departamentos acadêmicos. Em relação aos estudantes de pós-graduação, o líder pode manifestar uma atitude protetora tal como aquela ostentada por Frank Knight em relação aos economistas de Chicago, Malinowski e Gluckman, em relação aos seus estudantes de antropologia. As qualidades a serem desenvolvidas nos estudantes são a capacidade de entender, aplicar e desenvolver ainda mais os pontos de vista centrais da escola de maneira original. Isso não acarreta a repetição pura das idéias de um líder mas o seu desenvolvimento de maneira criativa e indo além de alguma formulação inicial. Lasswell fez isso em relação a Merriam, Mauss e Halbwachs em relação a Durkheim. O processo, todavia, é um processo que envolve intensa e séria discussão levada adiante por um longo período de tempo.

Os arranjos institucionais, por meio dos quais isso é alcançado, variam um pouco, mas dois elementos são de importância principal: a existência de seminários onde as idéias e abordagens são desenvolvidas e aplicadas, e a disponibilidade de meios para a publicação dos trabalhos da escola. O mais famoso seminário foi talvez aquele de Malinowski, descrito por um de seus participantes, Audrey Richards:

Aquelas discussões semanais tornaram-se famosas e atraíam estudantes dos tipos os mais diferentes. Oficiais coloniais em licença valorizavam sua abordagem viva, mesmo se não se incomodassem muito com seu método de ensino de perguntas-e-respostas. Pesquisadores seniors vindos de muitas partes do mundo e Malinowski com frequência vinham a trocar réplicas muito 
rapidamente em quatro ou cinco línguas diferentes. Especialistas universitários sentavam-se lado a lado com os mais simples amadores. Esses seminários variavam, mas em seus melhores momentos apresentavam desempenhos brilhantes. Malinowski era um homem de ampla cultura e grande charme pessoal. Ele podia ser provocativo e preconceituoso, mas também podia ser profundo, penetrante e construtivo. Seu humor inteligente era proverbial. Havia um curioso toque inspirador em tudo que fazia e um raro poder de evocar idéias em outros. Sua retidão forçava os estudantes a ir ao fundo de um problema e expressar seus elementos essenciais de maneira simples. (1943, p. 3).

Para os economistas de Chicago, o severo teste em que os estudantes de pós-graduação na década de 1930 recebiam sua formação profissional era o árduo, exigente e rigoroso curso de pósgraduação 301 de princípios econômicos ministrado por Jacob Viner (REDER, 1982, p. 8-9). Em sociologia, o seminário de Park e Burgess sobre estudos de campo a partir de 1918 desempenhou um papel semelhante (BULMER, 1984a).

Os seminários formais não eram, todavia, o único cenário. A importância da Society for Social Research [Sociedade de Pesquisa Social] em incentivar laços entre o corpo de pesquisadores e os estudantes e - através de seu Summer Institute [Instituto, ou seja, Seminário, ou “Oficina”, de Verão] - com antigos estudantes, foi recentemente evidenciada (Bulmer 1983). Os seminários da Local Community Research Committee [Comissão de Pesquisa da Comunidade Local] (Bulmer 1980), as sociedades de letras gregas, o Clube de Sociologia e o envolvimento em pesquisa empírica de primeira mão também reforçaram esses laços entre professores e estudantes. Isso contribuiu para o sentido de seriedade intelectual entre o corpo de estudantes. Os estudantes de sociologia de pósgraduação do período testemunharam o grau em que "viviam sociologia" e estavam preocupados com seus estudos grande parte do tempo (CAREY, 1975, p. 153-159). O pequeno tamanho da equipe de ensino fez com que os contatos com os professores fossem mais fáceis.

Park, em particular, estava sempre trocando idéias com estudantes. Não se avalia devidamente, em geral, o imoderado montante de tempo que Park gastou com seus estudantes aconselhando-os sobre como escrever e ajudando-os a reescrever e a polir seus trabalhos. De fato, uma razão pela qual ele próprio escreveu tão pouco foi o tempo que passou fazendo isso.

Park via-se como um capitão de pesquisa com uma companhia de homens e mulheres que deviam ser dirigidos para um tópico que valesse a pena. (...) [Seu] envolvimento com seus estudantes era não sistemático mas com freqüência extenso e contribuiu muito para a grande admiração com que muitos se recordam dele. Se um estudante ou um tópico pareciam promissores, Park arranjava longas entrevistas em que o assunto era definido, os métodos discutidos e as próprias experiências e interesses dos estudantes eram integrados ao seu tópico de pesquisa. (...) Alguns estudantes eram convidados para viagens ao campo, giros através de Chicago em que Park meditava sobre a 
significação do que viam; outros recordam encontros casuais na rua que se tornavam longas discussões do trabalho do estudante. (...) Tanto colegas como estudantes recordam as longas conversações, algumas vezes continuadas de um dia para outro, em que Park, andando de um lado para outro, tentava clarificar suas próprias idéias ou as dos estudantes. Seu assistente com frequiência ouvia essas falas, anotando as idéias mais promissoras para desenvolvimento posterior. Essas conversações, ou monólogos, discorriam sobre categorias concretas de investigação e as vidas, interesses e peculiaridades das pessoas; mas também tentavam associar os dados concretos a uma teoria social coerente. (...)

Ainda que Park desse seu tempo prodigamente, não somente em entrevistas e tours de exploração, mas em almoços com estudantes e extensos empréstimos de livros, seu principal interesse era o projeto e não o estudante. Embora muitos estudantes pareçam tê-lo adotado como Honorável Ancestral, sua atitude era mais aquela do editor de cidade - provocando, sugerindo, indagando, ironizando, reescrevendo, repreendendo - do que a de um pai ou conselheiro orientador. (MATTHEWS, 1977, p. 107-109).

A publicação das obras da escola é o outro meio pelo qual se alcança um intercâmbio intelectual intenso. O principal exemplo disso, de fato o meio pelo qual sua escola foi criada, é o papel desempenhado pelo periódico de Durkheim, o L'Année Sociologique. O processo de contribuir para essa publicação e de editá-la, em que as resenhas e outros trabalhos sociológicos eram uma característica muito importante, foi o principal meio pelo qual Durkheim constituiu uma rede acadêmica (BESNARD, 1983, p. 11-39). Os membros do grupo se reuniam muito pouco. Vindos de uma grande variedade de disciplinas, alguns pareciam não estar cientes da existência dos outros. Basear-se assim numa publicação como meio de integração da escola é incomum.

Mais comum é o papel da publicação, primeiro, em proporcionar um foco para a orientação da conclusão dos trabalhos e, segundo, ao garantir sua disseminação para uma audiência acadêmica mais ampla. O segundo ponto é mais usualmente considerado. Chicago desfrutava de vantagens por ser o American Journal of Sociology ali editado e pela University of Chicago Sociological Series proporcionar um meio para os melhores Ph.D.s serem publicados. Ao livro-texto de Park \& Burgess (1921), a "bíblia verde" como foi o seu primeiro título, é geralmente atribuída a difusão da abordagem de Chicago para outros departamentos por todo o país. O primeiro ponto, todavia, é muito mais interessante. Nels Anderson, por exemplo, descreveu (1975) como Burgess e Park lhe deram um detalhado aconselhamento sobre como revisar e reescrever o manuscrito que foi publicado como The Hobo (Anderson 1923), a primeira monografia da série. Park e Burgess eram copiosos em sua ajuda aos estudantes para moldar suas idéias e resultados em forma publicável, frequentemente levando-os para além do que eles poderiam ter realizado de outra forma (MATTHEWS, 1977, p. 109). 
Os arranjos para as publicações proporcionam uma lembrança da sétima característica das escolas que se engajam em pesquisa empírica, a de que elas exigem uma infraestrutura adequada. Essa infra-estrutura é composta de diversos elementos de espécies bastante diferentes. Uma característica comum das escolas de Park, Merriam, Malinowski e Gluckman foi que elas fizeram consideráveis avanços nos métodos de pesquisa. Os estudantes de Park foram pioneiros no estudo com múltiplos métodos de pequenos meios sociais, os de Merriam no moderno survey de ciência política, os de Malinowski no envolvimento etnográfico numa sociedade estranha e os de Gluckman, na análise situacional e no método de casos ampliado. $\mathrm{O}$ avanço de uma escola de ciência social empírica depende de métodos efetivos de pesquisa tanto quanto de boas idéias e de desempenhar um papel pioneiro como conseqüência. A variedade de métodos usados em Chicago na década de 1920 foi obscurecida pela assimilação da sociologia de Chicago pelo interacionismo simbólico (ROCK, 1979). De fato, os métodos quantitativos também foram usados (BULMER, 1981b) e a crença neles incorporada no exterior do Prédio de Ciência Social aberto em 1929:

"Quando você não pode medir * seu conhecimento * é * pobre * e * insatisfatório * Lord Kelvin.”

Certas ligações institucionais foram também de considerável importância. A existência de meios de publicação já foi mencionado. Albion Small fundou o American Journal of Sociology e ele continuou a ser publicado pelo departamento. A existência da The University of Chicago Press [Editora da Universidade de Chicago], com que Park e Burgess iniciaram um programa de publicações, foi também importante. A associação com instituições complementares, tais como o Institute for Juvenile Research [Instituto para a Pesquisa da Juventude], a Juvenile Protective Association [Associação de Proteção à Juventude] e a Chicago Crime Commission [Comissão de Crimes de Chicago], às quais os estudantes podiam ser vinculados, proporcionou valiosos contatos externos. No caso de Malinowski, o International African Institute, e no de Gluckman, o RhodesLivingstone Institute da Rodésia do Norte proporcionaram uma estrutura mais ampla para a promoção da investigação empírica (KUPER, 1983, P. 32; BROWN, 1979). Em Chicago, a Local Community Research Committee proporcionou uma considerável proporção dos recursos da pesquisa sociológica (BULMER, 1980).

Isso dirige a atenção para o importante papel desempenhado pelo apoio financeiro externo em tornar possíveis as escolas de ciência social empírica. No caso de Chicago, a Laura Spelman Rockefeller Memorial foi de primordial importância (BULMER; BULMER, 1981), embora outras fontes também tenham contribuído (SMITH; WHITE, 1929, p. 33-46). Em que extensão esse apoio alimentou as escolas de Chicago? A falta de apoio poderia claramente ser um obstáculo decisivo, como mostraram as tentativas anteriores em Atlanta de DuBois para iniciar uma pesquisa séria acerca 
dos negros americanos. Malinowski, na década de 1930, obteve apoio financeiro da Fundação Rockefeller para o International African Institute e usou-o como um meio de financiar seus estudantes no campo. Os estudantes de Gluckman compartilhavam das bolsas do Colonial Social Science Research Council e em Manchester tiveram acesso a recursos especiais na forma de Simon Fellowships.

Tais recursos externos poderiam ser usados para proporcionar bolsas para os estudantes, satisfazer as despesas do trabalho de campo e pagar pela transcrição das anotações depois da volta do campo. Em Chicago eles foram também usados para proporcionar a substituição de professores da equipe que se afastavam para pesquisa em tempo integral, o emprego de assistentes de pesquisa, suprir auxílio estatístico e serviços de secretaria e o subsídio de publicações (Bulmer 1980). A controvérsia sobre o papel social das fundações filantrópicas na ciência social no século XX irá continuar até a exaustão, mas é claro que seu apoio financeiro foi uma condição necessária para o florescimento da pesquisa empírica nas décadas de 1920 e de 1930, sob a direção de Robert Park na sociologia, Charles Merriam na ciência política e Bronislaw Malinowski na antropologia.

As escolas não duram além da geração de seus fundadores. Esta é sua oitava característica. Muitas das razões para sua existência asseguram que depois que seu líder ou líderes declinem, se aposentem ou morram, a escola provavelmente deixará de continuar por muito tempo em seu antigo caminho. Em Chicago, o declínio da sociologia começou no início da década de 1930 e dentro de uma década tanto Harvard (onde Parsons ficava cada vez mais influente) e Columbia (onde Lazarsfeld e Merton estavam em parceria) rivalizavam com Chicago como departamentos líderes (KUCKLICK, 1973; WILEY, 1979). A controvérsia sobre a American Sociological Society e a fundação da American Sociological Review em 1936 (LENGERMANN, 1979) assinalaram a mudança, mas ela começou ainda antes de Park se aposentar em 1934 e ir morar em Fisk.

A escola de Chicago foi constituída ao redor de Park, mas ele fez pouco para assegurar sua sobrevivência. A maioria de seus estudantes foi embora para lecionar em posições acadêmicas em outros lugares. A sociologia de Chicago foi influente por todo o Meio Oeste e no resto dos Estados Unidos, mas a originalidade de sua perspectiva foi se desvanecendo. $\mathrm{O}$ departamento não conseguiu manter sua coesão e não conseguiu recrutar sociólogos familiarizados com a teoria social européia ou com os novos campos, tais como a sociologia das organizações e a pesquisa de media, em que Harvard e Columbia eram fortes. Burgess estava ocupado com a sociologia da família, Ogburn com as Recent Social Trends [Tendências Sociais Recentes] e (um pouco depois) Stouffer com metodologia e migração. Eles não foram capazes de proporcionar liderança acadêmica. O manto de Park passou para Everett Hughes, que retornou de McGill em 1938, mas por essa época a escola de Chicago original já tinha tido seus dias. 
Assim também em outros casos: o grupo de Charles Merriam de cientistas políticos teve seu auge na década de 1930, mas o presidente da universidade, Robert M. Hutchins, ao lhes negar promoção, encorajou Harold Lasswell e Harold Gosnell a deixarem Chicago para irem à Costa Leste. A escola não sobreviveu à aposentadoria de Merriam. O grupo de Malinowski na London School of Economics rompeu-se em 1939 quando Malinowski partiu para o México, para não mais voltar, em parte devido a desacordos internos. A influência local de outros cientistas sociais dominantes - por exemplo, Lazarsfeld, em Columbia, Max Gluckman, em Manchester - dissipou-se quase imediatamente depois de suas mortes. Uma exceção interessante a essa generalização é a escola de Chicago de economia, que tem durado por um período mais longo. Embora não tenha vindo a existir realmente até as décadas de 1940 e 1950, ela nunca foi tão dependente quanto a sociologia e a ciência política de um ou dois indivíduos o tempo todo. Ela teve uma liderança mais coletiva (REDER, 1982; PATINKIN, 1981, cap. 1).

Deve-se distinguir claramente entre a sobrevivência de uma escola e a sobrevivência das idéias ou da abordagem de um sociólogo particular. A primeira é extremamente rara, a última mais comum. Os arranjos institucionais centrados em um ou dois indivíduos não têm uma existência infinita devido ao âmbito limitado das idéias inovadoras, a incapacidade de uma abordagem única de se regenerar de dentro e a mudança de gerações na vida acadêmica que assegura que os sucessores de poderosos professores mais velhos não aspirem a moldar o departamento à imagem de seus predecessores. A própria raridade das escolas de ciência social, sobretudo, sugere sua relativa fragilidade. A preservação de um grupo estreitamente unido de scholars com as mesmas opiniões e idéias no interior de um único departamento por mais do que quinze ou vinte anos é inteiramente excepcional.

Uma característica final das escolas nas ciências sociais, outras que a economia, é sua abertura para idéias e influências vindas de outras disciplinas. Há um perigo institucional em exagerar o fechamento alcançado por uma escola. Como uma estrutura, é um grupo informal baseado em afinidade intelectual reforçada por laços particularistas e afetivos. Diferentemente do corpo docente ou do departamento de uma universidade, ela não tem existência contínua legalmente constituída, gabinetes para serem ocupados, papéis claramente definidos (particularmente quando a sucessão está em questão). Escolas de ciência social empírica bem sucedidas tem sido notavelmente abertas ao estímulo da fertilização cruzada vinda de outras disciplinas. Como líderes de escolas, Park, Merriam, Malinowski e Gluckman mantinham todos extensos contatos interdisciplinares. Os durkheimianos, apesar da imagem de seu líder como o profeta do sociologismo, constituíram um verdadeiro programa interdisciplinar (BESNARD, 1983, p. 27). Park recorreu particularmente a idéias da biologia, da literatura e da antropologia; Merriam, da psicologia e da estatística; Malinowski, da biologia e da 
economia; e Gluckman, do direito e da sociologia. As disciplinas acadêmicas têm tendência a se olharem de dentro. É uma hipótese que a fertilidade de certas escolas tenha se devido a sua capacidade de superar essa tendência.

A busca de elementos comuns não deve ser levada muito longe. Há também importantes diferenças entre elas: de conteúdo intelectual, das personalidades das figuras líderes, na maneira pela qual a escola se institucionaliza e nos meios pelos quais a intensidade é mantida; no grau de sua dominação dentro de uma disciplina particular e na posição, nacional ou internacionalmente, da universidade em que a escola está localizada. A comparação aqui feita entre a escola de Chicago de sociologia e algumas outras escolas de ciência social sugere, não obstante, certas hipóteses para exame posterior. Há também indicações para algumas das raízes da criatividade da própria escola de Chicago de sociologia. Como uma planta rara e frágil, ela emergiu, cresceu até a plena força e então decaiu. O que é certo é que tais ocorrências incomuns são eventos espontâneos, que não podem ser planejados ou antecipados.

\section{London School of Economics and Political Science}

\section{Referências}

Afirmações não substanciadas de outra maneira a respeito da escola de Chicago neste artigo são documentadas em Bulmer 1984a.

ABRAMS, P. The Origins of British Sociology: 1834-1914. Chicago: University of Chicago Press, 1968.

ANDERSON, Nels. The Hobo: The Sociology of the Homeless Man. Chicago: University of Chicago Press, 1923.

ANDERSON, Nels. The American Hobo: an autobiography. Leiden: E. J. Brill, 1975.

BENNETT, J. Oral History and Delinquency: The Rhetoric of Criminology. Chicago: University of Chicago Press, 1981.

BERNARD, L. L. "Schools of Sociology" - Southwestern Political \& Social Science Quarterly, vol. 11 Sept. 1930.

BESNARD, P. (Ed.). The Sociological Domain: The Durkheimians and the Founding of French Sociology. Cambridge: Cambridge University Press, 1983.

BOARDMAN, P. The Worlds of Patrick Geddes: Biologist, Town Planner, Re-educator, Peacewarrior. London: Routledge \& Kegan Paul, 1978.

BROWN, R. "Passages in the Life of a White Anthropologist: Max Gluckman in Northern Rhodesia" - Journal of African History - vol. 20: 525-541, 1979.

BULMER, Martin."The Early Institutionalization of Social Science Research: The Local Community Research Committee at the University of Chicago, 1923-30" - Minerva, vol. 18: 51-110, 1980.

BULMER, Martin. "Charles S: Johnson, Robert E. Park and the Research Methods of the Chicago 
Commission on Race Relations, 1920-1922: An Early Experiment in Applied Social Research" Ethnic and Racial Studies, vol. 4: 289-306, 1981a.

BULMER, Martin. "Quantification and Chicago Social Science in the 1920s: A Neglected Tradition". Journal of the History of the Behavioral Sciences, vol. 17: 312-331, 1981b.

BULMER, Martin. "The Society for Social Research: An Institutional Underpinning to the Chicago School of Sociology" - Urban Life, vol. 11: 421-439, 1983a.

BULMER, Martin. "Chicago Sociology and the Society for Social Research: A Comment" - Journal of the History of the Behavioral Sciences - vol. 19: 353-356, $1983 \mathrm{~b}$.

BULMER, Martin. The Chicago School of Sociology: Institutionalization, Diversity and the Rise of Sociological Research. Chicago: University of Chicago Press, 1984a.

BULMER, Martin (Ed.). Essays on the History of British Sociological Research. Cambridge: Cambridge University Press, 1984b.

BULMER, Martin; BULMER, J. "Philanthropy and Social Science in the 1920s: The case of Beardsley Ruml and the Laura Spelman Rockefeller Memorial 1922-1929." - Minerva, vol. 19: 347407, 1981.

BURGESS, E. W. "Research in Urban Society: A Long View." Pp.: 2-13, in: E.W. Burgess and D. J. Bogue (Eds.) - Contributions to Urban Sociology. Chicago: University of Chicago Press, 1964.

CAREY, J. T. Sociology and Public Affairs: The Chicago School. Beverly Hills: Sage, 1975.

CAVAN, R. S. "The Chicago School of Sociology, 1918-1933." - Urban Life, vol. 11: 406-420, 1983.

CHICAGO Commission on Race Relation. The Negro in Chicago. Chicago - University of Chicago Press, 1922.

CONDIT, C. W. The Chicago School of Architecture. Chicago: University of Chicago Press, 1964.

COSER, L. A. "American Trends" - Pp. 287-320 in: T. B. Bottomore and R. Nisbet (Eds.), A History of Sociological Analysis. London: Heinemann, 1978.

COTTRELL. L. S. Jr.; A. HUNTER; J. F. SHORT Jr. (Eds.) Ernest W. Burgess on Community, Family and Delinquency. Chicago: University of Chicago Press, 1973.

DINER, S. J. A City and its Universities: Public Policy in Chicago, 1892-1919. Chapel Hill: University of North Carolina Press, 1980.

DUNCAN, H. D. Culture and Democracy: The Struggle for Form in Society and Architecture in Chicago and the Middle West During the Life and Times of Louis H. Sullivan. Totowa, NJ: The Bedminster Press, 1965.

FARIS, R.E. L. Chicago Sociology, 1920-1932. Chicago: University of Chicago Press, 1970.

FRIEDMAN, M. "Remarks at the $54^{\text {th }}$ Annual Board of Trustees' Dinner for the Faculty" - University of Chicago Records, vol 8, n. ${ }^{\circ}$ 1: p. 3-7, 1974.

GOODE, W. J., F. FURSTENBERG, Jr.; L. R. MITCHELL (Eds.) Willard W. Waller on the Family, Education and War: Selected Writings. Chicago: University of Chicago Press, 1973.

HUNTER, A. Symbolic Communities: The Persistence and Change of Chicago's Local Communities. Chicago: University of Chicago Press, 1974.

HUNTER, A. "Why Chicago? The Rise of the Chicago School of Urban Science" - American Behavioral Scientist, vol. 24: 215-227, 1980.

JANOWITZ, M. (Ed.) William I. Thomas on Social Organization and Social Personality. Chicago: 
University of Chicago Press, 1966.

KARL, B. D. Charles E. Merriam and the Study of Politics. Chicago: University of Chicago Press, 1974.

KITCHEN, P. A Most Unsettling Person: An Introduction to the Ideas and Life of Patrick Geddes. London: Gollancz, 1975.

KUKLICK, H. "A 'Scientific Revolution': Sociological Theory in the United States, 1930-1945." Sociological Inquiry, vol. 43: 3-22, 1973.

KUPER, A. Anthropology and Anthropologists: The British School. London: Routledge \& Kegan Paul, 1983.

KURTZ, L. R. "Robert E. Park's 'Notes on the Origin of the Society for Social Research'" Journal of the History of the Behavioral Sciences, vol. 18: 332-340, 1982.

LENGERMANN. P. "The Founding of the American Sociological Review: The Anatomy of a Rebellion." - American Sociological Review, vol. 44: 185-198, 1979.

LEWIS, J. D.; R.L. SMITH. American Sociology and Pragmatism: Mead, Chicago Sociology and Symbolic Interaction. Chicago: University of Chicago Press, 1980.

MATTHEWS, F. H. Quest for an American Sociology: Robert E. Park and the Chicago School. Montreal: McGill-Queens University Press, 1977.

MUMFORD, L. Sketches From Life: The Autobiography of Lewis Mumford - The Early Years. New York: Dial Press, 1982.

OBERSCHALL. A. "The Institutionalization of American Sociology". p. 187-251 in: A. Oberschall (Ed.) - The Establishment of Empirical Sociology. New York: Harper \& Row, 1972.

PARK, R. E.; E. W. BURGESS. Introduction to the Science of Sociology. Chicago: University of Chicago Press, 1921.

PARK, R. E.; E. W. BURGESS; R. D. MCKENZIE. The City. Chicago: University of Chicago Press, 1925.

Park, R. E.; H. A. Miller [\& W. I. Thomas]. Old World Traits Transplanted. New York: Harper, 1921.

PATINKIN, D. Essays On and In the Chicago Tradition. Durham, NC: Duke University Press, 1981.

RAUSHENBUSH, W. Robert E. Park: Biography of a Sociologist. Durham, NC: Duke University Press, 1979.

REDER, M. W. "Chicago Economics: Permanence and Change" - Journal of Economic Literature, vol. 20: 1-38, 1982.

RICHARDS, A. "Bronislaw Kaspar Malinowski, 1884-1942" - Man, vol. 43: 1-4, 1943.

ROCK, P. The Making of Symbolic Interactionism, London: Macmillan, 1979.

SHILS, E. "Tradition, Ecology and Institution in the History of Sociology." - Daedalus 99: 760-825, 1970.

SHILS, E. The Calling of Sociology and Other Essays on the Pursuit of Learning. Chicago: University of Chicago Press, 1980.

SHILS, E. "Some Academics, Mainly in Chicago" - The American Scholar, Spring, p. 179-196, 1981.

SHORT, J. F. Jr. (Ed.). The Social Fabric of the Metropolis: Contributions of the Chicago School of Urban Sociology. Chicago: University of Chicago Press, 1971. 
SIEGEL, A. (Ed.). Chicago's Famous Buildings. Chicago: University of Chicago Press, 1969.

SILVER, C. B. Frederic Le Play on Family, Work and Social Change. Chicago: University of Chicago Press, 1982.

SOROKIN, P.A. Contemporary Sociological Theories. New York: Harper, 1928.

SMITH, T. V.; L. D. WRITE (Eds.). Chicago: An Experiment in Social Science Research. Chicago: University of Chicago Press, 1929.

THOMAS, J. (Ed.). "The Chicago School: The Tradition and the Legacy" - Urban Life, vol. 11, n. 4 (Special Issue): 387-527 1983.

TIRYAKIAN, E. A. "The Significance of Schools in the Development of Sociology" In: W. E. Snizek, E. R. Fuhrman \& M. K. Miller (Eds.), Contemporary Issues in Theory and Research: A Metasociological Perspective. Westport, CT: Greenwood Press, 1979.

TURNER, R. (Ed.). Robert E. Park on social control and collective behavior. Chicago: University of Chicago Press, 1967.

WILEY, N. "The Rise and Fall of Dominating Theories in American Sociology". p. 47-79 in: W. E. Snizek, E .R. Fuhrman and M. K. Miller (Eds.), Contemporary Issues in Theory and Research: $a$ metasociological Perspective. Westport, CT: Greenwood Press, 1979. 